\title{
La carestía de granos de 1789 en Cervera
}

\author{
Josep M. ${ }^{a}$ Llobet Portella *
}

\section{INTRODUCCIÓN}

En el año 1980 conoci al profesor Dr. D. Antonio de Bethéncourt Massieu. Deseaba iniciar mi tesis doctoral y me trasladé a Madrid para proponerle la dirección de la misma y pedirle que me aconsejara la elección de un tema a partir del amplio conjunto de posibilidades que ofrecía la numerosa documentación de los archivos catalanes ${ }^{1}$. Enseguida me di cuenta de su profunda dimensión humana que enriquecia su competencia docente en el ámbito universitario y empezó una amistad que ha perdurado más allá de aquella primera relación entre profesor y alumno.

Hoy, con motivo de un merecido homenaje a su persona, tras una larga etapa de magisterio universitario, me complazco en ofrecerle unos breves comentarios relacionados con uno de aquellos temas suceptibles de ser desarrollados en profundidad: las carestías de los granos en la Cataluña de la segunda mitad del siglo XVIII, aunque reduciéndolo a un solo año y a una única población: Cervera en 1789.

\section{LA VALORACIÓN DEL PROBLEMA}

La escasez de cereales y, en general, las crisis de subsistencias que afectaron, de forma intermitente y a lo largo de la segunda mitad del

* Centro Asociado de la UNED en Cervera.

"El tema elegido para la tesis fue La "Taula de Canvi" de Cervera y su entorno socioeconómico (1599-1715), estudio publicado en el año 1985 (Lleida, Instituto de Estudios llerdenses). 
siglo XVIII, buena parte del territorio español incidieron también en la ciudad de Cervera, población de unos 4.600 habitantes con una economía básicamente de tipo agrícola. Un año caracterizado por la falta de trigo fue el de 1789.

La crisis del año 1789 en Cataluña fue especialmente grave. En Barcelona y en otras poblaciones, como Mataró, Valls o Vic, estallaron disturbios en protesta por el precio del pan, en franca subida por la falta de cereales experimentada en aquel año ${ }^{2}$.

En cuanto a Cervera, la primera información corresponde al día 2 de marzo y nos llega a través del libro de actas municipal ${ }^{3}$. Aquel día se reunieron en el Ayuntamiento, en sesión extraordinaria, el corregidor de la ciudad, que era Juan Antonio Pérez, teniente coronel de infantería, seis de los siete regidores, dos diputados, el síndico procurador general y el síndico personero, para tratar de un tema que preocupaba a toda la población: los altos precios que habían alcanzado los granos debido a su escasez. Fue acordado que, siendo mercado el día siguiente, los almotacenes se preocuparan de conocer con exactitud tanto los precios de los cereales como su disponibilidad para la venta y, posteriormente, lo comunicaran al Ayuntamiento.

En efecto, en la tarde del día siguiente tuvo lugar una nueva reunión de los miembros del Ayuntamiento, en ella los dos almotacenes precisaron que durante su permanencia en el mercado, a lo largo de toda la mañana, habian podido comprobar que si bien la población estaba bien abastecida de granos los precios eran muy altos, como se podia deducir de las muestras que habian tomado, cada una con su precio ${ }^{4}$. Oídas todas las intervenciones de los presentes, se acordó escribir al fiscal de la Real Audiencia comunicándole el resultado de la información.

Tres días después, el 6 de marzo, nuevamente fueron convocados los miembros del Ayuntamiento; esta vez para recibir información sobre un edicto, un bando y varias cartas del Real Acuerdo que se habian recibido el día anterior ${ }^{5}$.

2 Sobre los disturbios en Barcelona. Irene CASTELLS: «Els rebomboris del pa de 1789 a Barcelona", Recerques, 1, 1970, pp. 51-81; Enric MOREU-REY: Revolució a Barcelona el 1789, Barcelona, Institut d'Estudis Catalans, 1967.

${ }^{3}$ Arxiu Històric Comarcal de Cervera, Fons Municipal, Consells, 1789, f. 72 v.

${ }^{4}$ AHCC, FM, Consells, 1789, f. 76.

5 AHCC, FM, Consells, 1789, f. 78 v. 
El edicto y el bando estaban fechados en Barcelona el día 2 de marzo. El primero disponía que cualquier persona del principado de $\mathrm{Ca}$ taluña que tuviera trigo o harina estaba obligado a comunicarlo a las autoridades bajo pena de comiso. El segundo establecia la pena de muerte para todos aquellos que intentasen la rebaja de alguno de los géneros que servían para el abasto, tanto si participaban directamente alborotando o con mano armada, como si lo hacian induciendo a otras personas.

La severidad de esta última disposición sería consecuencia de los graves disturbios iniciados en Barcelona el día 28 de febrero, en los cuales una multitud de varios miles de personas asaltó algunos edificios y se enfrentó con las tropas. ${ }^{6}$.

En cuanto a las cartas, en una de ellas se informaba que el Real Acuerdo había resuelto que en todas las poblaciones del principado de Cataluña se tomaran medidas para la detención de aquellas personas desconocidas que iniciaran alborotos, tomando como ejemplo la ciudad de Barcelona, en la que los cuerpos de la nobleza, colegios y gremios habían "aquietado los bullicios". Después de leída, el Ayuntamiento, a pesar de que la tranquilidad hasta aquel día habia sido total en la población, resolvió asignar a cada miembro de la corporación el control de una zona de la ciudad, mientras que el corregidor, por su parte, facultaba a cada uno de los regidores, diputados y síndicos para poder prender y encarcelar a cualquier persona sospechosa, operación en la que estaban obligados a prestar su ayuda todos los vecinos de la población. Ello se hizo público por medio de pregón, advirtiendo que el incumplimiento de estas disposiciones sería castigado con una multa de 30 reales o una pena de cárcel.

Asimismo, el Ayuntamiento, en la misma sesión, acordó que las puertas de entrada a la ciudad permanecieran cerradas desde las ocho de la tarde hasta las cinco de la mañana y que se entregaran las llaves a los vecinos más cercanos a cada una de dichas puertas.

El 14 de marzo se reunió el Ayuntamiento para ser informado de la respuesta dada por el Real Acuerdo al escrito que anteriormente habia sido mandado al fiscal de la Real Audiencia sobre el precio de los gra-

\footnotetext{
6 Véase nota núm. 2.
} 
nos, según acuerdo tomado en la sesión del día 3 de aquel mes ${ }^{7}$. En dicha respuesta se mandaba que se actuara de acuerdo con las órdenes expedidas sobre el libre comercio de granos y se pedia que, a imitación de lo que se habia hecho en Barcelona y en otras poblaciones de Cataluña, las personas acaudaladas acudieran en auxilio de los menesterosos. En la misma sesión se resolvió dejar la noche de los jueves abiertas las puertas de Capuchinos y San Cristóbal con la finalidad de que el correo pudiera entrar en la ciudad, puesto que con anterioridad había encontrado dichas puertas cerradas.

\section{EN BUSCA DE UNA SOLUCIÓN: LA JUNTA DE CARIDAD}

A mediados del mes de mayo, los granos habían alcanzado un precio tan elevado que las personas sin recursos de la ciudad se hallaban en una situación de verdadera miseria. Reunido el Ayuntamiento el 17 de aquel mes, en virtud de la carta del Real Acuerdo en la que se recomendaba que facilitaran ayuda a los vecinos necesitados se intentó encontrar un remedio eficaz, pero después de largas discusiones sólo se logró el acuerdo de que se elaborase una lista de las personas más acaudaladas de la población y se presentase, en la sesión del día siguiente, a los miembros del Ayuntamiento ${ }^{8}$.

Así fue, el día 18 de mayo ya estaba la lista preparada y, después de haberla revisado, los miembros del Ayuntamiento acordaron convocar a una reunión prevista para el día siguiente a las personas incluidas en dicha lista para pedirles su colaboración ${ }^{9}$. Seguidamente, resolvieron escribir cartas a la Comunidad de Presbíteros, claustro de la Universidad literaria y deán, en las cuales se pedía el nombramiento, por parte de cada una de dichas instituciones o dignidades, de dos representantes, quienes, conjuntamente con los designados por el Ayuntamiento, formarían una Junta de Caridad que sería la encargada de prestar auxilio a los necesitados. Además, cada comisionado presentaría una lista con las personas que desearan colaborar y el importe de sus donativos. En prin-

\footnotetext{
7 AHCC, FM, Consel/s, 1789, f. 84 v.

8 AHCC, FM, Consel/s, 1789, f. 144 v.

9 AHCC, FM, Consells, 1789, f. 150 v.
} 
cipio la ayuda se fijó hasta la recolección de la cosecha, o sea que tendría una duración de unas cuatro semanas.

Por la tarde del mismo día se presentaron las cartas ya redactadas para su aprobación, se nombraron los representantes del Ayuntamiento en la Junta de Caridad y se contó con la promesa del corregidor, que no asistió al acto por encontrarse enfermo, de abonar seis libras ${ }^{10}$ semanales en concepto de ayuda ${ }^{11}$.

La copia de la carta dirigida al claustro de la Universidad literaria, similar a las otras, nos permite saber que la finalidad de la formación de la Junta de Caridad era ofrecer trigo a las personas necesitadas cuatro pesetas ${ }^{12}$ por cuartera ${ }^{13}$ más barato que el precio del mercado, diferencia que seria compensada por los donativos de las personas que quisieran participar en la obra ${ }^{14}$.

El día 19 de mayo se reunió la Comunidad de Presbíteros de Cervera y, después de ser informada del contenido de la carta del Ayuntamiento, acordó elegir los dos comisionados solicitados y ofrecer 30 libras semanales, 15 de los fondos de la Comunidad y las otras 15 de las aportaciones voluntarias de los presbíteros ${ }^{15}$.

Aunque menos explícita, la respuesta del claustro de la Universidad literaria muestra un alto grado de entusiasmo por la propuesta, anuncia el nombramiento de los dos comisionados y promete "la cantidad permitida en los reales estatutos» en cuanto al fondo de la Universidad y «lo

to Sistema monetario catalán de la época:

1 libra $=20$ sueldos $=240$ dineros

1 libra $=10$ reales de ardites $=240$ dineros de ardites

1 peseta $=7,50$ sueldos $=90$ dineros

Lorenzo Rodríguez: Nueva reducción y correspondencia que tiene la moneda de oro en Cataluña con la de Castilla, Gerona, Antonio Oliva, (s.a.).

11 AHCC, FM, Consells, 1789, f. 154.

12 Véase nota número 10.

${ }^{13}$ Una cuartera equivale a 73,36 litros. Se divide en 12 cuartales y en 48 picotines ( 0 cuartillos). Para la reducción: Magín LLADÓs y RIUS, Sistemas métrico-decimal y monetario español, Barcelona, (s.e.), $1871^{2}$. Siendo la densidad del trigo de $0,75 \mathrm{~kg}$. por litro, cada cuartera pesaría unos $55 \mathrm{~kg}$.

${ }^{14}$ Apéndice, doc. II.

${ }^{15}$ AHCC, Fons Comunitat de Preveres, Consells, 1777-1793, f. 246. 
que pudiese por su parte" por lo que se refiere a las aportaciones de cada individuo ${ }^{16}$.

El mismo día en que se informó a los miembros del Ayuntamiento del contenido de la carta del claustro de la Universidad - el 23 de mayo-, se les notificó también la recepción de un edicto del Real Acuerdo, fechado en Barcelona el 19 de mayo de 1789, por el cual se hacía pública la concesión de libertad en la entrada de todos los granos que se introdujesen por los puertos de la Península hasta la recolección de la cosecha. Asimismo, para fomentar la llegada de trigo y maíz, se establecía la gratificación de un real por cada fanega de dichos granos que se desembarcase durante el período de tiempo señalado ${ }^{17}$.

\section{UN NUEVO RECURSO: EL TRIGO DEL PÓSITO}

Creyendo los miembros del Ayuntamiento que todas estas medidas, desde las estatales a las locales, no bastarían para socorrer debidamente a los necesitados, escribieron, con fecha 25 de mayo, una carta al conde de Lacy, capitán general de Cataluña, en la cual le exponían el estado en que se hallaba la población, donde el trigo llamado xeixa se había vendido a 8 libras, 19 sueldos y 0,75 dineros la cuartera en el mercado del día 12 de mayo, y a 9 libras, 8 sueldos y 2,25 dineros durante el mercado del día 15 del mismo mes ${ }^{18}$, mientras que los jornaleros, trabajando diez o doce horas diarias, sólo ganaban de 7 a 8 sueldos. Como remedio y teniendo en cuenta que el Pósito de la población disponía de más de 2.200 cuarteras de trigo, pedian que, en caso necesario, pudieran solicitar un préstamo de 600 ó 800 libras con la garantía de 150 ó 200 cuarteras de trigo de aquellas que eran debidas al Pósito y serian reintegradas en el mes de agosto ${ }^{19}$. En el momento de su devolución se

16 Apéndice, doc. III.

17 AHCC, FM, Consell, 1789, ff. 155 y 157.

${ }^{1}$ Véase la diferencia con el precio del mismo año indicado en el Apéndice, doc. I.

19 Según la liquidación hecha el 15 de abril de 1790 por Josep Constants, comerciante de Cervera y depositario del Pósito, en el mes de agosto de 1789 se devolvieron a dicho Pósito 1.992 cuarteras de trigo, mientras que 231 cuarteras más no pudieron ser reintegradas por dificultades económicas de los deudores. Estos eran 39 y las cantidades de grano adeudadas oscilaban entre 1 y 20 cuarteras por persona (AHCC, FM, Cuentas del Pósito de Granos, 1765-1806, s/f.) En consecuencia, las 2.200 cuarteras de trigo no serian de existencias en almacén sino, en todo o en parte, de género prestado. 
venderían y se pagaría al acreedor que hubiera desembolsado el dinero. Con dicha cantidad de 600 ó 800 libras, más los donativos, se compraría trigo para venderlo a los necesitados de la población a cuatro pesetas por cuartera más barato de lo que costase ${ }^{20}$.

La respuesta no se hizo esperar, dos días después el Real Acuerdo autorizaba la operación propuesta aunque señalaba la necesidad de que el superintendente general de Pósitos del reino fuese avisado de ello ${ }^{21}$.

Después de obtener la conformidad de la Junta del Pósito, el Ayuntamiento cervariense, el día 7 de junio, trasladó su petición al conde de Floridablanca, superintendente general de Pósitos ${ }^{22}$, quien, por medio de un escrito fechado en Madrid el 24 de junio, expresó su aprobación de la propuesta ${ }^{23}$.

Finalmente no fue preciso valerse de dicho permiso puesto que hacia finales de junio estaban ya aliviadas las necesidades de la población debido a los donativos voluntarios que se habían recogido entre las personas acaudaladas ${ }^{24}$. Aunque la recolección de la cosecha debió poner punto final a aquella grave carestía de cereales del año 1789 en la ciudad de Cervera, a nivel general el problema persistió puesto que en el mes de noviembre de aquel año una nueva orden prolongaba la libertad de entrada de grano extranjero que se había concedido en el mes de mayo de 1789 , hasta la cosecha del año siguiente ${ }^{25}$.

\section{CONCLUSIONES}

De todos los comentarios anteriores se podría extraer las siguientes conclusiones:

\footnotetext{
20 AHC, FM, Consel/s, 1789, f. 166.

21 AHC, FM, Consells, 1789, f. 165.

22 Apéndice, doc. IV.

23 Apéndice, doc. $V$.

24 AHCC, FM, Registre de Lletres, 1777-1818, s/f. (carta de fecha 5 de junio de 1793).

${ }^{25}$ AHCC, FM, Conse/ls, 1789, ft. 243 y 263.
} 
- La carestía de granos del año 1789 afectó también a la población de Cervera.

- Se creó una Junta de Caridad para que, con los donativos de aquellas personas que quisieran colaborar voluntariamente, se pudiese ofrecer a los vecinos necesitados cantidades de trigo -que serían destinadas a la elaboración de pan- a un precio inferior al del mercado.

- Los donativos procedían, principalmente, de personas hacendadas, presbiteros y profesores de la Universidad.

- En el mes de mayo los precios del trigo eran tan altos que se pidió autorización para poder solicitar un préstamo de 600 ó 800 libras, garantizado con el importe del trigo que seria devuelto en el mes de agosto al Pósito de la ciudad, cuya cantidad sería destinada a la Junta de Caridad.

- Esta última medida no fue necesaria ponerla en práctica debido a que los donativos voluntarios fueron suficientes para cumplir el objetivo de la Junta de Caridad.

- A diferencia de otras poblaciones catalanas, no consta que se produjeran disturbios en la ciudad debidos a la carestía del trigo. 


\section{APÉNDICE}

\begin{tabular}{|c|c|c|c|c|c|}
\hline \multicolumn{6}{|c|}{$\begin{array}{l}\text { Precio del trigo del Pósito vendido en el mercado de Cervera durante e } \\
\text { decenio 1780-1789 }\end{array}$} \\
\hline \multirow[b]{2}{*}{ AÑOS } & \multirow{2}{*}{\multicolumn{2}{|c|}{$\begin{array}{l}\text { CANTIDADES } \\
\text { CUARTALES }\end{array}$}} & \multirow[b]{2}{*}{ CUARTILLOS } & \multicolumn{2}{|c|}{ PRECIOS POR CUARTERA } \\
\hline & & & & $\begin{array}{l}\text { REALES DE } \\
\text { ARDITES }\end{array}$ & $\begin{array}{l}\text { DINEROS DE } \\
\text { ARDITES }\end{array}$ \\
\hline 1780 & 20 & & & 30 & \\
\hline 1781 & 20 & 4 & 2 & 30 & \\
\hline 1782 & $\begin{array}{l}10 \\
15\end{array}$ & & & $\begin{array}{l}35 \\
37\end{array}$ & 12 \\
\hline 1783 & 9 & & & 40 & \\
\hline 1784 & 39 & 6 & & 26 & 6 \\
\hline 1785 & 22 & 9 & & 40 & \\
\hline 1786 & - & & & - & \\
\hline 1787 & 35 & & & 32 & $10^{2} / 3$ (promedio) \\
\hline 1788 & 20 & & & 40 & \\
\hline 1789 & 14 & & & 48 & 18 \\
\hline
\end{tabular}

Fuente: AHCC, FM, Cuentas del Pósito de Granos, 1765-1806. 
1789, mayo, 18, Cervera

Carta del Ayuntamiento de Cervera al claustro de la Universidad de la misma ciudad solicitando su participación en la Junta de Caridad con el nombramiento de dos comisionados y pidiendo la colaboración de sus miembros con la aportación de donativos.

AHCC, FM, Consells, 1789, f. 152.

«Muy ilustre señor:

Mui señor nuestro: El notorio apuro a que se hallan reducidas muchas familias de esta ciudad por el excesivo precio de los granos, ha obligado a este Ayuntamiento a tomar una determinación a que no podemos dexar de prometernos que vuestra señoria, por su conocido zelo y bondad, se dignará cooperar, maiormente no quedando ya otro recurso y haviendo, antes de llegar a él, procurado y esperado este cuerpo el alivio de los que de otra parte podian proporcionarle. En primeros de marzo de este año representamos a la Real Audiencia el crecido precio que havian tomado los granos, a fin de que pudiese proveherse de remedio a la urgente necesidad, y su excelencia se dignó resolver que obrásemos con arreglo a la pragmática y demás órdenes expedidas en punto al libre comercio de granos y que, en el interin que se tomavan providencias en alivio de los naturales, esperava que, a imitación de la capital y demás pueblos del principado, las personas hacendadas y acaudaladas de esta ciudad acudirian al socorro de los menesterosos. En realidad, de resultas de las providencias que se nos insinuaron en dicha carta se tuvieron luego avisos de haver llegado a varios puertos de la costa diferentes embarcaciones cargadas de trigo, y no tardó en venir la orden con que su real magestad (que Dios guarde) se dignó conceder esención de derechos a los granos que hasta el tiempo de la cosecha se tragesen a esta provincia; con esto y con el beneficio de la lluvia nos lisongeávamos que estava remediada ya la necesidad, pero viendo la notoria alteración de precios que ha havido de dos mercados a esta parte, no nos queda otro arbitrio 
que el que insinuó el Real Acuerdo, en conformidad a lo qual ha resuelto este Ayuntamiento que se forme un monte pío de la limosna que voluntariamente se ofreciere y diere para comprar trigo y venderlo a la gente menesterosa quatro pesetas más barato de lo que costare puesto en esta ciudad, repartiéndolo con equidad y conocimiento, que a este fin se convoquen los hacendados y acaudalados de esta ciudad y se pase oficio a vuestra señoria, a la muy reverenda Comunidad y al señor deán, para que todos los respectivos individuos se animen a cooperar a una obra tan pia en lo que su caridad y zelo les dicte en las críticas circunstancias del tiempo, nombrando cada cuerpo dos comisionados, los quales con los de este Ayuntamiento y con los que destinaren los otros cuerpos formen una junta de caridad, y ésta, con la noticia de las resoluciones que se huvieren respectivamente tomado por los ilustres cuerpos y de la limosna que huvieren ofrecido los respectivos individuos, que se recogerá semanalmente a menos que alguno quiera darla con anticipación, puedan tomar las providencias correspondientes para la execución del proiecto expresado en alivio de los pobres, con la inteligencia de que durará esto solamente hasta la próxima cosecha.

En conseqüencia participamos a vuestra señoría esta resolución, esperando que se dignará vuestra señoría contribuir por medio de sus individuos al alivio de la gente necesitada y nombrar dos comisionados con el fin expuesto, a lo que quedará este cuerpo agradecido con el maior afecto. Con éste suplicamos a vuestra señoría que nos dé ocasiones de complacerle y a Dios, nuestro señor, que le guarde muchos años.

Cervera y mayo, 18, de 1789.

Mui ilustre señor:

Besan la mano de vuestra señoría sus más atentos y seguros servidores.

[Mui ilustre corregidor y Ayuntamiento de la ciudad de Cervera.] 
Mui ilustre señor vicecancelario y claustro de la real Universidad de Cervera.

1789, mayo, 22, Cervera

Carta del claustro de la Universidad de Cervera al Ayuntamiento de la ciudad dando su conformidad a las peticiones formuladas por esta última institución.

AHCC, FM, Consells, 1789, f. 156.

Mui ilustre señor:

Mui señor nuestro: La parte que vuestra señoría se ha servido concedernos en sus piadosas intenciones de vuestra señoría de acudir al socorro de los pobres en las necesidades presentes, es una satisfacción de las más cumplidas y más sensibles que pudiera lograr este cuerpo, ya por los vivos deseos que siempre ha tenido de complacer a vuestra señoría, ya por la favorable ocasión que vuestra señoria se ha servido concederle de acompañar su conocido zelo y benignidad. La favorecida de vuestra señoría de $18 \mathrm{del}$ corriente se recibió en el claustro con el mayor aplauso y aprobación, y se acordó, desde luego, que se librase la cantidad permitida en los reales estatutos del fondo de la Universidad y que además cada individuo procurase contribuir en lo que pudiese por su parte a tan santo y loable fin, a cuio efecto se nombraron dos comisionados que cuidarán de recoger y poner en manos de vuestra señoría el dinero que se pudiere juntar. Celebrará infinitamente el claustro que vuestra señoría pueda ver cumplidos sus caritativos deseos y que logren el más feliz suceso sus acertadas providencias, dando, entretanto, mil gracias a vuestra señoría del honor que se ha servido hacernos en admitirnos en alguna parte de su zelo por el bien común, y suplicando al Señor concerve por muchos 
años a la pública felicidad la vigilancia y liberalidad de vuestra señoría.

De este claustro de la real Universidad literaria de Cervera a los 22 de mayo de 1789 .

Mui ilustre señor:

Besan la mano de vuestra señoría sus más atentos y seguros servidores.

Doctor fray Sebastián Agustín Prats, vicecancelario.

Doctor Pedro Girós, comisionado.

Doctor Juan Noguera, presbítero, comisionado.

Por acuerdo del muy ilustre claustro, doctor Francisco Vall, secretario substituto.

Mui ilustre corregidor y Ayuntamiento de la ciudad de Cervera.

IV

1789, junio, 7 , Cervera

Carta del Ayuntamiento de Cervera al conde de Floridablanca, superintendente general de Pósitos del reino, solicitando su conformidad para garantizar con el trigo del Pósito cervariense un préstamo de 600 ó 800 libras y devolver dicha cantidad, en el mes de agosto, con el importe del trigo reintegrado a dicho Pósito.

AHCC, FM, Consells, 1789, f. 164. 
Exelentísimo señor:

Mui señor mío: A causa del crecido precio a que subió y se mantiene el trigo en esta ciudad, como en las demás poblaciones del principado, se vio este Ayuntamiento en la precisión de formar un monte pío de las limosnas de los hacendados y acaudalados para comprar trigo y venderlo a la gente menesterosa quatro pesetas más barato de lo que costase, insiguiendo en esto lo que le tenía prevenido la Real Audiencia de Barcelona en respuesta de las cartas con que este cuerpo le dio parte de la necesidad.

Pero conociendo de que el referido medio no bastaría para el deseado socorro, pensó valerse de ciento cincuenta o doscientas quarteras de trigo del Pósito de granos que tiene esta ciudad y de aquellas que deberán los deudores reintegrar en dicho Pósito el próximo agosto, para asegurar y hacer el pago de seiscientas 0 ochocientas libras catalanas, que se juzgan necesarias y que podrán faltar para alivio de estos pobres naturales, al sugeto que prestase o anticipase la referida partida. A fin de poderse poner en obra el expresado proyecto, acudió este Ayuntamiento, para la aprobación y permiso, al superior más inmediato, viendo de que urgía la necesidad y que el tiempo era tan perentorio que no daba lugar para representarlo a vuestra excelencia, y con carta de 27 del próximo pasado mayo, que se remite original, se sirvió el Real Acuerdo aprobar el medio propuesto, la que se hizo pasar a la Junta del Pósito, y en su vista los señores de ella no sólo manifestaron no tener reparo en la execución, precediendo el correspondiente permiso, sino que alabaron por mui justo y equitativo el tal proyecto, atendiendo sin duda a que este Pósito está formado por vía de préstamo por los naturales de la misma ciudad, que ha crecido hasta a más de dos mil doscientas quarteras con las creces que han sufrido los mismos particulares, que para facilitar la sementera es mui sobrado, y que el fin de su erección es el de acudir principalmente a las necesidades del mismo pueblo.

Estos motivos sugerieron al Ayuntamiento el proyecto, el no tener otro recurso de que echar mano se lo hace abrazar y procurar, y la grande y experimentada piedad de vuestra excelencia le hace esperar de que se dignará vuestra excelencia conceder su aprobación y permiso para el expresado fin y atender los respetos con que este Ayuntamiento se renueva a las órdenes de vuestra excelencia y los votos con que ruega a Dios guarde la persona de vuestra excelencia muchos años. 
Cervera de Cataluña, junio, 7, de 1789.

Excelentísimo señor:

Besa la mano de vuestra excelencia su más rendido y pronto servidor.

[El Ayuntamiento de la ciudad de Cervera.]

Excelentísimo señor conde de Floridablanca.

1789, junio, 24, Madrid

Carta del conde de Floridablanca al Ayuntamiento de Cervera aprobando la petición que dicha institución le habia dirigido.

AHCC, FM, Consells, 1789, f. 163.

Por la representación que vuestra señoría me dirigió con fecha de 3 [sic] del corriente, he visto con mucho gusto el zelo con que ha mirado por el alivio de los pobres vecinos de esa ciudad para precaverlos de la necesidad que huvieran padecido en el surtido de pan barato, respecto del crecido precio del trigo, y, desde luego, apruebo que el Pósito concurra con las ciento cinqüenta o doscientas quarteras desde su fondo para la satisfacción del dinero que han anticipado los acendados, teniendo yo por muy justo el que contribuya a la subsistencia de los mismos que le crearon y conserban, y para que al depositario se abone la cantidad efectiba en la cuenta de fin de diciembre próximo, se acompañará a ésta orden con testimonio que lo acredite. 
Dios guarde a vuestra señoría muchos años. Madrid, 24 de junio de 1789.

El conde de Floridablanca.

Al Ayuntamiento de la ciudad de Cervera. 